\title{
Semi-conventional play: definition, exploration strategy and the example of the Chalk Group in Denmark
}

\author{
Alessandro Sandrin* \\ Department of Petrology and Economic Geology, Geological Survey of Denmark and Greenland (GEUS), Copenhagen, Denmark
}

\begin{abstract}
Play analysis has been widely used in hydrocarbon exploration for decades with great success. In recent years, progress has also been made to describe reservoir properties of very low permeability reservoirs. However, comparatively little research has been conducted into play analysis for such reservoirs, which may lead to misleading estimates of their hydrocarbon potential. Here, the concept of a semi-conventional play is defined and characterised as having a reservoir of such low permeability that a hydrocarbon column can form down-dip of an effective dry trap. A new exploration approach is proposed for such plays using the Chalk Group Play in the Danish North Sea as an example. It is suggested that together with the usual risk elements, a more detailed analysis of 'charge' is necessary, paying particular attention to identifying possible hydrocarbon entry-points, palaeostructures and the maximum distance from these entry-points that the hydrocarbons may have reached since they first entered the reservoir. The application of this novel approach for semi-conventional plays in mature basins could help unlock further resources in proximity of existing fields, and reduce the risk of failure in frontier exploration.
\end{abstract}

\section{Introduction}

In petroleum exploration, a 'play' is a conceptual model for hydrocarbon accumulations used to identify prospective areas in a basin. The model is further analysed during development of the fields to continue exploitation within a defined geological trend. The hydrocarbon industry developed the concept of play analysis to provide a more structured way of exploring hydrocarbons (White 1988; Grant et al. 1996; Nelskamp 2017). Starting at regional-geology large scales, the analysis moves up within the 'exploration triangle' (e.g. Fraser 2011; Milkov 2015) all the way to prospect analysis and exploratory drilling. Individual companies and research centres have developed their own play analysis techniques that differ in details but not in their fundamental aspects. The petroleum play could be divided into a number of play elements, including (1) the reservoir (the rock hosting the hydrocarbons), (2) seal (the cap-rock), (3) trap (a geometrical configuration of rocks that produces a closed volume of hydrocarbons) and (4) charge (how, where and when hydrocarbons moved from the source rock into the reservoir). A key point of the exploration process is the separation between the play elements (regional geological features) and the prospect elements,

\author{
*Correspondence: alsa@geus.dk \\ Received: 06 Jan 2020 \\ Accepted: 23 Mar 2020 \\ Published: 26 May 2020
}

Keywords: play analysis, chalk, low-permeability reservoir, Denmark

\section{Abbreviations:}

mD: mDarcy

TWT: Two Way Time

GEUS Bulletin is an open access, peerreviewed journal published by the Geological Survey of Denmark and Greenland (GEUS). This article is distributed under a $C C-B Y 4.0$ licence, permitting free redistribution, and reproduction for any purpose, even commercial, provided proper citation of the original work. Author(s) retain copyright.

Edited by: Catherine Jex (GEUS, Denmark)

Reviewed by: Ida Fabricius (Technical University of Denmark, Denmark) and Kresten Anderskouv (University of Copenhagen, Denmark)

Funding: None declared

Competing interests: None declared

Additional files: None provided 
which are specific to a particular area (i.e. in close proximity of the prospect, which is a small and welldefined area were hydrocarbons have been predicted to be present).

Explorationists often assume, but never explicitly state, that the migration of hydrocarbons is basically 'instantaneous' on geological timescales. This implies that the reservoir and the hydrocarbon carrier beds must have good permeability. In other words, when a drop of oil enters the reservoir, it is assumed that it instantly reaches the various traps in the play. This is obviously true in reservoirs with permeabilities of the order of $500 \mathrm{mD}$ or more (Chadwick et al. 2004; Blasingame 2008; Hjuler et al. 2016). However, in low-permeability reservoirs, hydrocarbons may move at such low rates that dry effective traps could occur and therefore the boundaries of the play have to be re-drawn accordingly. To account for this, a new exploration approach is proposed for semi-conventional plays in this article, using the Chalk Group in the Danish North Sea as a type example. The proposed approach may permit a better delineation of the effective play and minimises the chance of leaving economically interesting areas unexplored.

\section{Definition of semi-conventional play}

A semi-conventional play is characterised by reservoir permeability so low that the speed at which hydrocarbons move within the reservoir is slow enough to allow the existence of hydrocarbon columns down-flank of a dry effective trap (e.g. see modelling by Kok \& Arnhild 2012). This implies that hydrocarbons can still be 'on the move' and may not have yet reached all the available and effective traps. The speed at which hydrocarbons move within the reservoir is not only dependent on permeability but also on other parameters such as pressure gradients, oil viscosity and structural dip (Fig. 1; Vejbæk et al. 2005; Kok \& Arnhild 2012). However, permeability is a reservoir property that must be accounted for when performing play analysis, and thus it is the focus of this review.

The most significant difference between a conventional and a semi-conventional petroleum play is the element of 'charge' (Table 1). In conventional oil plays, charge normally includes information on source rock presence, quality, maturity, timing and migration. Within high-permeability reservoirs, migration is assumed to be 'instantaneous' whereas in low-permeability reservoirs migration velocities are of the order of 1-10 km per million years (Kok \& Arnhild 2012). Thus, we need to define hydrocarbon entry-points and the distance hydrocarbons may have travelled since the first drop of oil entered the reservoir.

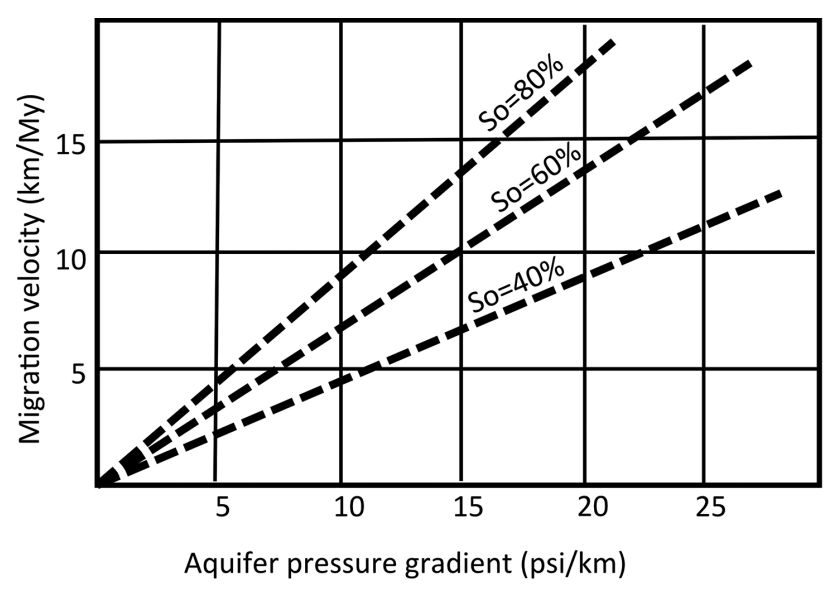

Fig. 1 Migration velocity of oil for various aquifer pressure gradients and oil saturations. The migration velocity of oil ( $\mathrm{Vo})$ is calculated using the following equation: $V_{0}=0.21 \times(K o / u o) \times(d P / d L) /(\varnothing$ $\times$ So), where $K o$ is the oil permeability, uo is the oil viscosity, $d P / d L$ is the pressure gradient, $\varnothing$ is the porosity and $S o$ is the oil saturation.

A description of charge should thus include a comprehensive analysis of the following:

1. Determination of likely hydrocarbon entry-points

2. Analysis of pressure gradients driving hydrocarbon migration

3. Migration velocity

4. Evolution and spatial variation of permeability within the reservoir.

These factors are sometimes considered in the analysis of conventional plays. However, they are particularly important when considering semi-conventional plays for reasons described next.

\section{Hydrocarbon entry-points}

When performing conventional play analysis, it is often assumed that vertical migration in the reservoir from the source rock happens everywhere within the play area where the source rock is (1) present, (2) of good quality and (3) matured at the right time - in relation to the trap formation. A more robust approach would be to map likely entry-points, which could be, for example, the fractured areas that connect the source rock to the reservoir. For a semi-conventional play, the low migration velocities imply that hydrocarbons may have reached only limited areas within a certain distance from the entry-points.

\section{Analysis of pressure gradients}

Aquifer pressure gradients can control the movement of hydrocarbons into and within a reservoir (Goff 1983; Winefield et al. 2005; O'Connor et al. 2008). This process is extremely important at a regional scale and determines the preferential direction of hydrocarbon migration. 
Table 1 Comparison between play elements for a conventional, unconventional and semi-conventional play

\begin{tabular}{lll}
\hline $\begin{array}{l}\text { Conventional } \\
\text { petroleum play }\end{array}$ & $\begin{array}{l}\text { Unconventional } \\
\text { petroleum play }\end{array}$ & $\begin{array}{l}\text { Semi-conventional } \\
\text { petroleum play }\end{array}$ \\
\hline Reservoir & Source rock occurrence & Reservoir \\
Seal & Hydrocarbon generation & Seal \\
Trap & Recoverability & Trap \\
Charge & & Charge $^{\text {a }}$ \\
\hline
\end{tabular}

${ }^{a}$ Must include reach (i.e. the maximum distance reached by hydrocarbons from likely entry points), which is dependent on (1) entry points, (2) pressure gradients, (3) migration velocity and (4) permeability variations of the reservoir in time and space.

Moreover, at the field- or prospect-scale, pressure gradients must be estimated (together with other parameters such as reservoir porosity, tectonic evolution and diagenesis) to characterise the development of oil-water contacts through time and the possible (present-day) occurrence of tilted oil-water contacts (Dennis et al. 2000; Harris \& Goldsmith 2001; Dennis et al. 2005; Vejbæk et al. 2005).

\section{Migration velocity}

In low permeability reservoirs, migration velocities could be as low as a few kilometres per million years. Mapping of likely entry-points allows for the creation of likelihood maps for the 'reach' of hydrocarbons, calculated from various scenarios for migration velocities and directions. Here, 'reach' is defined as the maximum distance reached by hydrocarbons from likely entry-points.

\section{Evolution and variation of permeability within the reservoir}

The reservoir facies may change in space and time. In some areas, the permeability may be lower due to lithological variations. Moreover, the permeability may also change in time due to compaction and diagenesis. Gross depositional environment maps for the reservoir are required to better predict the permeability of reservoir at various areas. When possible, the reservoir burial history, including compaction and diagenesis, should be analysed by stratigraphic backstripping or structural restorations.

\section{The Chalk Group in Denmark}

The concept of semi-conventional play originated from work on the Chalk Group Play (Chalk Play) in the Danish Sector of the North Sea (Fig. 2). With a purely traditional play analysis approach, major challenges were encountered at both play and prospect scale. The Chalk Play is a proven play (Megson 1992; Huuse 1999; Frykman et al. 2004; Megson \& Tygesen 2005; Van Buchem et al. 2017). The first discovery was made in 1966 (Kraka Field) with the first production at Dan Field in 1972. The reservoir

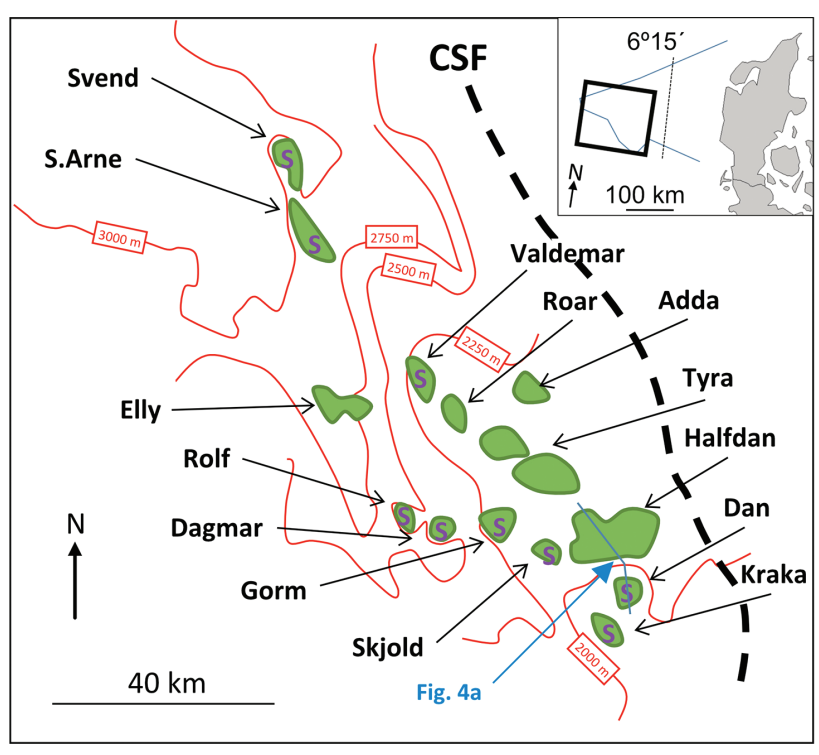

Fig. 2 Danish fields on Top Chalk depth map. S, salt structure; CSF, coffee soil fault. Modified following Vejbæk et al. (2005). Most of the fields are located on clear structural traps; however, the massive Halfdan Field is not related to any structural closure and the stratigraphic component of the trapping system cannot fully explain the existence of such a large accumulation.

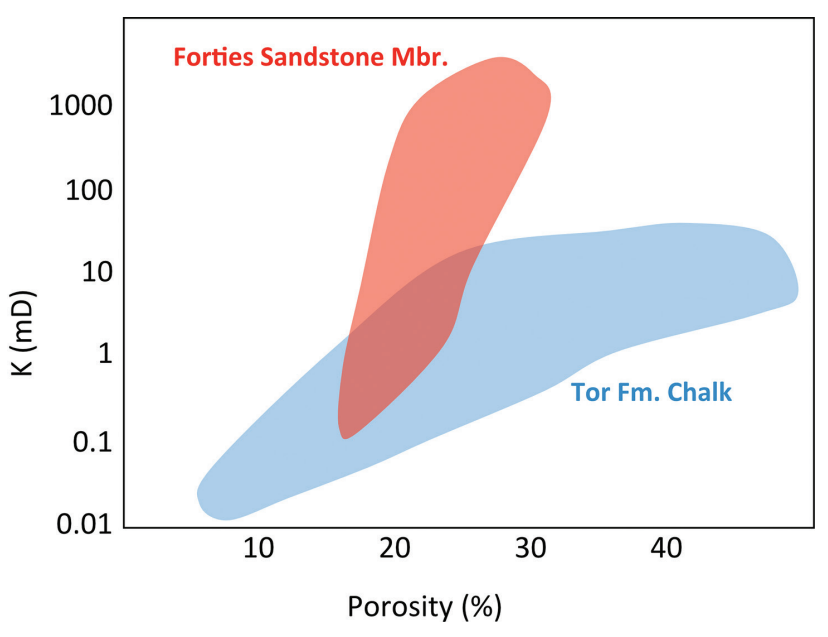

Fig. 3 Permeability ( $K$ ) versus porosity for a conventional (Forties Sandstone Mbr.) and a semi-conventional reservoir (Tor $\mathrm{Fm}$. of the Chalk Group). Note that even for large porosity values $(>30 \%)$, the Tor Fm. permeability never exceeds $100 \mathrm{mD}$. Data from Fabricius (2007) and Jones et al. (2005).

is a sedimentary carbonate rock, mainly composed of coccoliths (Hancock 1975; Hardman 1982; Fabricius 2007; Rasmussen \& Surlyk 2012) with variable porosity and permeability (see Fig. 3 for a comparison between the Forties Sandstone Mbr. and the Tor Fm. of the Chalk Group). Reservoir layers within the chalk have 30-45\% porosity, with 1-10-mD permeability (Mortensen et al. 1998; Fabricius 2007; Fabricius et al. 2007).

When analysing oil fields in the Danish sector, Halfdan Field (containing c. 1500 million stock barrels; 

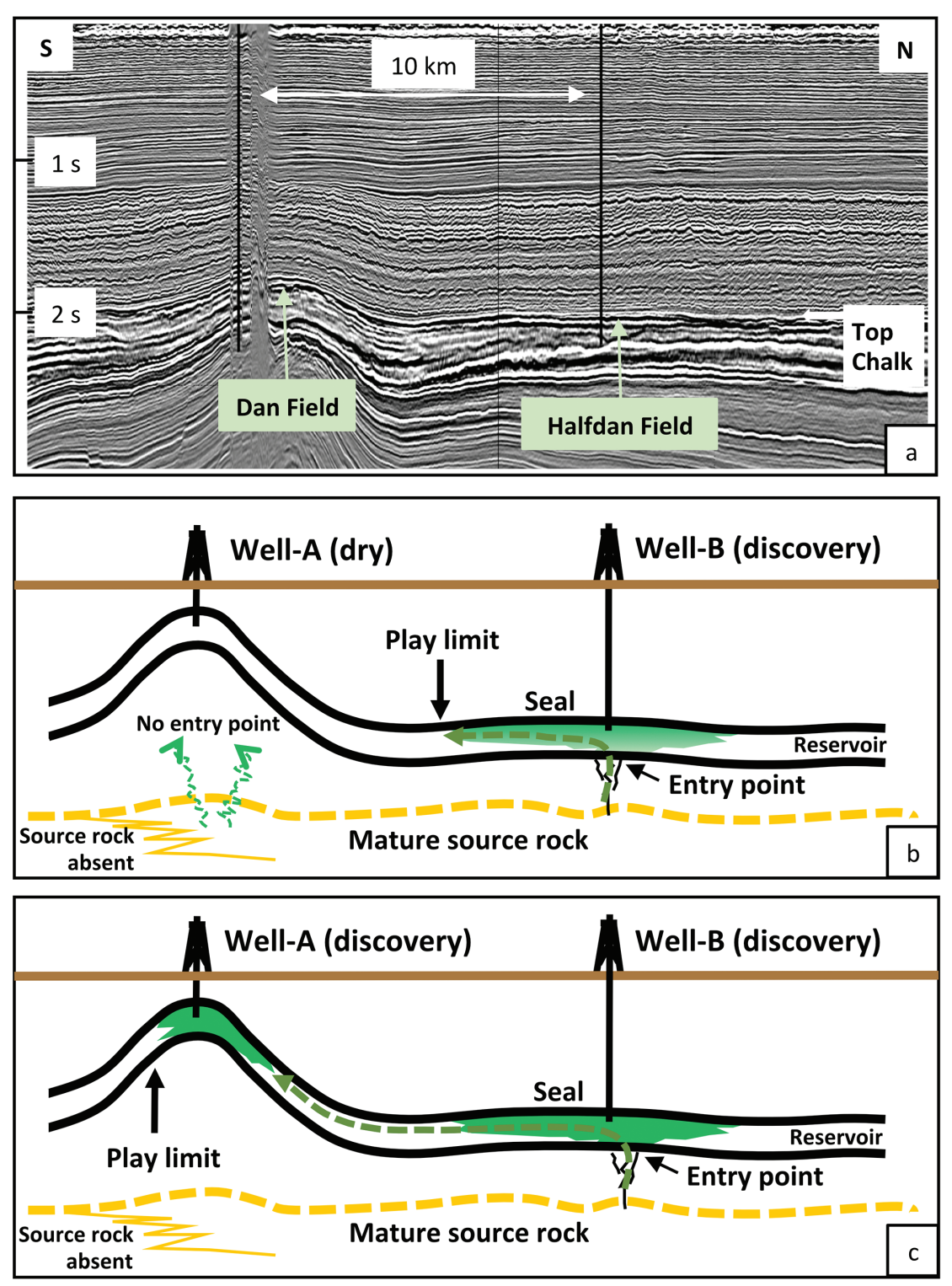

Fig. 4 a: Seismic vertical section in time (TWT) across Dan and Halfdan fields. b: Semi-conventional play at the onset of charge, where the oil has built a possible economic accumulation at well-B, but has not yet reached the effective trap at well-A. c: The same semi-conventional play after several million years, where the slow moving oil has reached the effective trap at well-A, and a hydrocarbon column is still present at well-B. See Fig. 1 for the location of the profile.
Albrechtsen et al. 2001; Fig. 4a) stands out as an evident anomaly since (1) there is no clear structural closure and (2) the stratigraphic component of the trapping system does not fully explain the existence of field. Vejbæk et al. (2005) suggested that hydrocarbon column in Halfdan Field was created before oil reached the up-dip four-way closure of Dan Field. In their modelling, a palaeoclosure was assumed to exist in Halfdan Field at the time of charge. However, the tilt or disappearance of the palaeostructure did not result in the 'instantaneous' equilibrium of fluids, leaving a substantial hydrocarbon column in the present-day non-existing geometrical trap. This clearly has an impact on both play- and prospect-scale analyses of semi-conventional plays in the region. Figure 4 depicts a conceptual model for the development of a semi-conventional play through time (Figs $4 \mathrm{~b}$ and $\mathrm{c}$ ), compared with the present day example of the Dan-Halfdan Fields (Fig. 4a). Evidently, when performing play analysis, the up-dip four-way structural closure (well-A) may or may not be located within the play (Figs $4 \mathrm{~b}$ and $\mathrm{c}$ ). In the case of low-permeability reservoirs, hydrocarbon reach could be estimated after mapping a likely entry-point and modelling migration velocities and directions, thus delineating the boundaries of the play 'sweet spot' (i.e. the most prospective region). In Fig. 4, both well-A and well-B are positioned at the point where the source rock is present and has matured; however, well-B is located in the proximity of a fractured zone that allowed vertical migration of hydrocarbons and the build-up of a column (as modelled by Kok \& Arnhild 2012). At well-A, an effective vertical conduit is missing, which implies that charge can occur only by the lateral movement of hydrocarbons within the reservoir. In a conventional play, a closure, such as at well-A, would be interpreted as being within the play sweet spot, as hydrocarbons entering well-B will reach well-A in short geological times and before the present day. Yet, for a semi-conventional play, well-A may be interpreted to be outside the effective play area, 
and thus have a lower chance of success than well-B. This observation is in contrast with the classical approach of prospect risking, since a mapped four-way structural closure above a mature source rock has a lower chance of success than a prospect with no stratigraphic or structural closure.

This novel approach to play analysis could be adopted in mature basins to properly evaluate the remaining prospectiveness without overlooking possible economic targets. Moreover, this new approach may also be applied in relatively unexplored basins for the correct evaluation of existing wells (i.e. 'dry well analysis'), for the characterisation of viable prospects and for the delineation of play sweet spot.

\section{Conclusions}

Play analysis of low-permeability reservoirs demands that the risk element of charge has to be treated in an unconventional manner. The low migration velocity of hydrocarbons in a low-permeability reservoir limits the areas of hydrocarbon reach. Therefore, it is paramount to include a comprehensive analysis of the following factors to accurately define the play limits and increase the chances of making a discovery:

1. Map of likely entry-points

2. Analysis of pressure gradients

3. Migration velocity

4. Permeability evolution and variation in time and space.

This innovative approach for semi-conventional plays would support a sound estimate of remaining resources in mature basins, and would constitute the best practice method in frontier exploration by diminishing the risk of failure.

\section{Acknowledgements}

The author would like to express his gratitude to Finn Engstrøm and other colleagues at Maersk Oil (now Total) and GEUS for very fruitful and challenging discussions when exploring for hydrocarbons in chalk and during the preparation of this article. John Hopper from GEUS is acknowledged for his input to the first draft of the article. The seismic section in Fig. 4a was provided by Erik Rasmussen, GEUS. Comments given by two reviewers greatly improved the first version of the article.

\section{Additional information}

Author contributions

AS is the sole author.

\section{References}

Albrechtsen, T. et al. 2001: Halfdan: developing non-structurally trapped oil in North Sea chalk. SPE Annual Technical Conference and Exhibition. New Orleans, LA, USA, 30 September-3 October, 2001. https:// doi.org/10.2118/71322-MS
Blasingame, T.A. 2008: The characteristic flow behavior of low-permeability reservoir systems. SPE Unconventional Reservoirs Conference. Keystone, CO, USA, 10-12 February, 2008. https://doi. org/10.2118/114168-MS

Chadwick, R.A. et al. 2004: Geological reservoir characterization of a $\mathrm{CO}_{2}$ storage site: the Utsira Sand, Sleipner, northern North Sea. Energy 29, 1371-1381. https://doi.org/10.1016/j.energy.2004.03.071

Dennis, H. et al. 2000: Hydrodynamic activity and tilted oil-water contacts in the North Sea. Norwegian Petroleum Society Special Publications 9, 171-185. https://doi.org/10.1016/S0928-8937(00)80016-8

Dennis, H., Bergmo, P. \& Holt, T. 2005: Tilted oil-water contacts: modelling the effects of aquifer heterogeneity. Geological Society, London, Petroleum Geology Conference Series 6, 145-158. https://doi. org/10.1144/0060145

Fabricius, I.L. 2007: Chalk: composition, diagenesis and physical properties. Bulletin of the Geological Society of Denmark $\mathbf{5 5}$, 97-128.

Fabricius, I.L. et al. 2007: Estimating permeability of carbonate rocks from porosity and vp/vs. Geophysics 72, E185-E191. https://doi. org/10.1190/1.2756081

Fraser, A.J. 2011: A regional overview of the exploration potential of the Middle East: a case study in the application of play fairway risk mapping techniques. Geological Society, London, Petroleum Geology Conference Series 7, 791-800. https://doi. org/10.1144/0070791

Frykman, P. et al. 2004: The history of hydrocarbon filling of Danish chalk fields. Geological Survey of Denmark and Greenland Bulletin 4, 9-12. https://doi.org/10.34194/geusb.v4.4768

Goff, J.C. 1983: Hydrocarbon generation and migration from Jurassic source rocks in the E Shetland Basin and Viking Graben of the northern North Sea. Journal of the Geological Society 140, 445-474. https:// doi.org/10.1144/gsjgs.140.3.0445

Grant, S., Milton, N. \& Thompson, M. 1996: Play fairway analysis and risk mapping: an example using the Middle Jurassic Brent Group in the northern North Sea. Norwegian Petroleum Society Special Publications 6, 167-181. https://doi.org/10.1016/S0928-8937(07)80017-8

Hancock, J.M. 1975: The petrology of the Chalk. Proceedings of the Geologists' Association 86, 499-535. https://doi.org/10.1016/ S0016-7878(75)80061-7

Hardman, R.F.P. 1982: Chalk reservoirs of the North Sea. Bulletin of the Geological Society of Denmark 30, 119-137.

Harris, R.G. \& Goldsmith, P.J. 2001: Water saturation analysis and interpretation of a tilted free-water level in the Joanne/Judy Chalk Field, U.K. North Sea. SPWLA 42nd Annual Logging Symposium. Houston, TX, USA, 17-20 June, 2001.

Hjuler, M.L. et al. 2016: Detailed assessment of geothermal potential by integration of a wide range of geological data: preliminary results of a case study from a lower Triassic Lowenthalpy reservoir in the Tønder area in southern Denmark. European Geothermal Congress 2016. Strasbourg, France, 19-24 September, 2016.

Huuse, M. 1999: Detailed morphology of the top chalk surface in the eastern Danish North Sea. Petroleum Geoscience 5, 303-314. https:// doi.org/10.1144/petgeo.5.3.303

Jones, D.W. et al. 2015: Reservoir geology of the Paleocene Forties Sandstone member in the Framdiscovery, UK Central North Sea. Geological Society, London, Special Publications 403, 219-246. https://doi. org/10.1144/SP403.13

Kok, A. \& Arnhild, M. 2012: Oil migration and dynamic traps in chalk, Danish North Sea. Search and Discovery, article \#120070.

Megson, J.B. 1992: The North Sea chalk play: examples from the Danish Central Graben. Geological Society, London, Special Publications 67, 247-282. $h$ ttps://doi.org/10.1144/GSL.SP.1992.067.01.10

Megson, J.B. \& Tygesen, T. 2005: The North Sea chalk: an underexplored and underdeveloped play. Geological Society, London, Petroleum Geology Conference Series 6, 159-168. https://doi.org/ 10.1144/0060159

Milkov, A.V. 2015: Risk tables for less biased and more consistent estimation of probability of geological success (POS) for segments with conventional oil and gas prospective resources. Earth-Science Reviews 150, 453-476. https://doi.org/10.1016/j.earscirev.2015.08.006 
Mortensen, J., Engstrøm, F. \& Lind, I. 1998: The relation among porosity, permeability, and specific surface of chalk from the Gorm Field, Danish North Sea. SPE Reservoir Evaluation \& Engineering 1, 245-251. https://doi.org/10.2118/31062-PA

Nelskamp, S. 2017: Geological resource analysis of shale gas and shale oil in Europe. Report T4b of the EUOGA Study (EU Unconventional Oil and Gas Assessment) commissioned by JRC-IET.

O'Connor, S.A., Swarbrick, R.E. \& Jones, D. 2008: Where has all the pressure gone? Evidence from pressure reversals and hydrodynamic flow. First Break 26, 55-61. https://doi.org/10.3997/1365-2397. 2008013

Rasmussen, S.L. \& Surlyk, F. 2012: Facies and ichnology of an upper cretaceous chalk contourite drift complex, eastern Denmark, and the validity of contourite facies models. Journal of the Geological Society 169, 435-447. https://doi.org/10.1144/001676492011-136
Van Buchem, F.S.P. et al. 2017: Tectonostratigraphic framework and depositional history of the Cretaceous-Danian succession of the Danish Central Graben (North Sea) - new light on a mature area. Geological Society, London, Petroleum Geology Conference Series 8, 9-46. https://doi.org/10.1144/PGC8.24

Vejbæk, O.V. et al. 2005: The history of hydrocarbon filling of Danish chalk fields. Geological Society, London, Petroleum Geology Conference Series 6, 1331-1345. https://doi.org/10.1144/0061331

White, D.E. 1988: Oil and gas play maps in exploration and assessment: geologic note 1. AAPG Bulletin 72, 944-949. https://doi. org/10.1306/703C911D-1707-11D7-8645000102C1865D

Winefield, P., Gilham, R. \& Elsinger, R. 2005: Plumbing the depths of the Central Graben: towards an integrated pressure, fluid and charge model for the Central North Sea HPHT play. Geological Society, London, Petroleum Geology Conference Series 6, 1301-1315. https://doi. org/10.1144/0061301 